\title{
Smart signals in heterogeneous traffic conditions
}

\author{
Mayank DUBEY, Assistant Professor, Xavier Centre for Urban Management and Governance,
} Bhubaneswar; India

\begin{abstract}
Major urban corridors in Indian cities are carrying significantly high traffic leading to near saturated conditions for extended peak hours. As mixed landuse and major trip attracting/generating establishments are generally observed to be located along such corridors for better accessibility, significant side friction is also observed along these corridors. Among various measures to improve the throughput along such corridors, signalized intersections seem to be the most preferred intervention for intersection control. Although frequent occurrence of such traffic signals and non-coordinated signal phases have in turn made the whole situation more complex. To overcome this challenge, variations of smart signals are being proposed by technology and traffic enterprises globally. Generally, smart interventions in operation of signalised intersections require communication among vehicles and control system through various sensors and applications of Intelligent transport services (ITS). Smart signal operations require the sensors grouted in pavement or attached with camera to share the relevant data in real time basis with central command and control centre. With adaptive signal operations, it is attempted to schedule signal phases in such a way that green phase of every cycle generally experiences near saturated flow conditions. The smart cities mission (SCM) of India, covering around 100 cities also focuses upon improving the urban mobility through various measures including smart signals. Some of the popular proposals relating to smart operation of signalised intersection across shortlisted smart cities include adaptive and coordinated traffic signals. It is understood that traffic signal optimization is not a one-time action but rather a continuous process, as data archiving, data crunching, research and adaptations are indispensable for its success. As the geometry, location and setting of each intersection in every network is bound to be unique, the optimization process needs to consider the same. The literature and case study of Indian city Bhubaneswar (ranked first in nationwide smart city challenge) revealed that challenges specific to Indian driving conditions are major cause of worry for yielding stated benefits of smart signals. Factors like varying hierarchy and functions along major arterial corridors, fluctuating carriageway width and quality, considerable side friction within right of way, heterogeneity in vehicular mix, significant variation in peak hour directional flows leading to tidal flow, surrounding network characteristics and efficacy of optimisation techniques are responsible for limited rewards out of the whole process. The study reflects upon these challenges and concludes with recommendations to improve the performance of signalized intersections along corridors with heterogeneous traffic conditions.
\end{abstract}

\section{Keywords}

Signal phase, arterial corridors, intelligent transport system, side friction 


\section{Introduction}

\subsection{Congestion on urban roads}

High vehicular density and relatively low operating speeds along arterial corridors of major cities in India represent the highly saturated traffic flow conditions (Shriniwas). Volume by Capacity ratio $(\mathrm{V} / \mathrm{C})$, the commonly used yardstick to assess the vehicular saturation on roads, consistently records values above unity referring to highly saturated road conditions. The journey speed in many cities are observed to be in the range of $7-20 \mathrm{kmph}$, representing severe jamming like conditions (Alam et. Al.). Table 1 summarizes general travel characteristics along arterial corridors for 5 different cities of India.

Table 1 - Vehicular traffic congestion along arterial corridor of various cities

\begin{tabular}{|c|c|c|c|c|c|c|c|}
\hline Sr. & City & Corridor & Stretch & $\begin{array}{c}\text { C/way } \\
\text { width in } \\
\text { m }\end{array}$ & $\begin{array}{c}\text { Peak } \\
\text { hour } \\
\text { volume } \\
\text { in PCU* }\end{array}$ & $\mathrm{V} / \mathrm{C}^{\#}$ & $\begin{array}{c}\text { Peak } \\
\text { hour } \\
\text { speed in } \\
\text { kmph }\end{array}$ \\
\hline 1 & $\begin{array}{l}\text { Bhuban } \\
\text { eswar }\end{array}$ & $\begin{array}{l}\text { Janpath } \\
4.9 \mathrm{~km}\end{array}$ & $\begin{array}{l}\text { Vani Vihar to } \\
\text { Sishu Bhaban }\end{array}$ & $\begin{array}{c}12 \mathrm{~m} \\
\text { (3-lane) }\end{array}$ & 2230 & $\begin{array}{c}2230 / 3857 \\
=0.58\end{array}$ & 19.2 \\
\hline 2 & Agra $^{\wedge}$ & $\begin{array}{l}\text { M G Road - } \\
5.8 \mathrm{~km}\end{array}$ & $\begin{array}{l}\text { Bhagwan } \\
\text { Talkies to } \\
\text { Pratappura }\end{array}$ & $\begin{array}{c}6 \mathrm{~m} \\
\text { (2 lane) }\end{array}$ & 2564 & $\begin{array}{c}2564 / 2142 \\
=1.2\end{array}$ & 11.8 \\
\hline 3 & Jaipur & $\begin{array}{l}\text { Tonk Road } \\
-5 \mathrm{~km}\end{array}$ & $\begin{array}{l}\text { GTC Mall to } \\
\text { Bajaj Nagar }\end{array}$ & $\begin{array}{c}10 \mathrm{~m} \\
\text { ( } 3 \text { lane) }\end{array}$ & 3112 & $\begin{array}{c}3112 / 3857 \\
=0.8\end{array}$ & 13.3 \\
\hline 4 & Indore & $\begin{array}{l}\text { M G Road - } \\
4.1 \mathrm{~km}\end{array}$ & $\begin{array}{l}\text { Rajwada to } \\
\text { patrakar } \text { Chk }\end{array}$ & $\begin{array}{l}\text { varying } \\
\text { (3 lane) }\end{array}$ & 3664 & $\begin{array}{c}3664 / 3857 \\
=0.95\end{array}$ & 12.4 \\
\hline 5 & Patna & $\begin{array}{l}\text { Bailey \& } \\
\text { Suri road - } \\
7.10 \mathrm{~km}\end{array}$ & $\begin{array}{l}\text { BPSC to } \\
\text { Shanichara } \\
\text { mod }\end{array}$ & $\begin{array}{l}\text { Varying } \\
\text { (2 lane) }\end{array}$ & 2644 & $\begin{array}{c}2644 / 2142 \\
=1.23\end{array}$ & 6.9 \\
\hline
\end{tabular}

Source - Primary data other than for Agra^ MG Road Improvement Study, SPA Delhi 2014

*Vehicle to PCU conversions based on IRC 106:1990

\# Volume by Capacity (V/C) calculations based on Design service volume from IRC 106:1990

It can be observed from Table 1 that across cities, not only the journey speeds are reduced, but most of the traffic flow operations along arterial corridors is saturated and forced. The volume by capacity ratio (V/C) is only indicative of the level of saturation although actual traffic flow depends upon other subjective parameters also. Along all the case study corridors mentioned above, ribbon development, on street parking, frequent punctures and side access, heterogeneous mix of vehicles and mixed landuse adjoining the arterial corridor are some of the factors which are responsible for reduced throughput and enhanced vehicular congestion. Lack of awareness, education and driving discipline can also be attributed to inefficient utilization of these roads (Chandra. et. al.). Apart from all the reasons listed above, frequent intersections along the arterial corridor and their inefficient operation also contributes to the congestion.

\subsection{Intersections along urban roads}

Intersections are the potential nodes in the road network which help in manoeuvring crossing vehicular desires. As various conflict points are scattered across the intersection (depending upon the geometry and desires), time and/or space appropriation is done to ensure safe and efficient mobility. Although intersections are very much required to provide various options and permutations for individual's route choice, frequent occurrence of 
intersections along arterial corridor results in significant delay and congestion. It is generally understood from codes of practices (IRC 106:1990 and NUTP) that mobility and accessibility for any corridor vary inversely with each other resulting in limited access per unit length for higher hierarchy corridors. But because of ribbon development, bazaar system and mostly unregulated development along the corridors, it has been observed that the functional hierarchy of arterial corridors have been diluted (Curtis et. al.). Table 2 illustrates the occurrence of punctures and side friction along selected arterial corridors of few Indian cities.

Table 2 - High accessibility and correspondingly low mobility along arterial corridors of selected Indian cities

\begin{tabular}{|c|c|c|c|c|c|c|c|c|}
\hline \multirow[b]{2}{*}{ Sr. } & \multirow[b]{2}{*}{ City } & \multirow[b]{2}{*}{ Corridor } & \multicolumn{5}{|c|}{$\begin{array}{c}\text { Number and type of } \\
\text { intersection(s) }\end{array}$} & \multirow[b]{2}{*}{$\begin{array}{l}\text { Other side friction } \\
\text { elements }\end{array}$} \\
\hline & & & 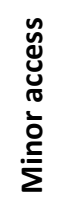 & 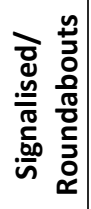 & 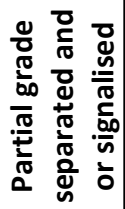 & 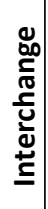 & $\stackrel{\pi}{\stackrel{0}{0}}$ & \\
\hline 1 & Bhubaneswar & $\begin{array}{l}\text { Janpath - } 4.9 \\
\mathrm{~km}\end{array}$ & 24 & 11 & 2 & 0 & 37 & on street Parking \\
\hline 2 & Agra & $\begin{array}{l}\text { M G Road - } 5.8 \\
\text { km }\end{array}$ & 35 & 17 & 1 & 0 & 53 & Vending, parking \\
\hline 3 & Jaipur & $\begin{array}{l}\text { Tonk Road - } 5 \\
\text { km }\end{array}$ & 14 & 15 & 1 & 0 & 30 & Mix landuse \\
\hline 4 & Indore & $\begin{array}{l}\text { M G Road - } 4.1 \\
\text { km }\end{array}$ & 27 & 14 & 0 & 0 & 41 & $\begin{array}{l}\text { Varying ROW and } \\
\text { mixed landuse }\end{array}$ \\
\hline 5 & Patna & $\begin{array}{l}\text { Bailey and Suri } \\
\text { road }-7.1 \mathrm{~km}\end{array}$ & 21 & 22 & 1 & 0 & 44 & $\begin{array}{l}\text { Varying ROW and } \\
\text { mixed landuse }\end{array}$ \\
\hline
\end{tabular}

Source - Primary data other than for Agra^ MG Road Improvement Study, SPA Delhi 2014

Based upon information presented in Table 1 and Table 2, it can be inferred that because of various reasons, including frequent intersections, the arterial corridors get reduced to the functional hierarchy of any other corridor of the settlement. It can also be noted from Table 2 that among all major intersection types, signalised intersections are most popular along the mentioned corridors across all cities studied. Signalised intersections are popular with civic administration because of simple operations and control and they offer predictability for the road users. In the complete life cycle of signalised intersections, it can be also argued that Signalisation is cost effective as compared to other traffic intersection control mechanism (Prashanth et. al.).

On the other hand, it has also been observed that the so-called benefits of signalised intersections are not very elastic and there is a limitation w.r.t. total traffic handling capacity of signalised intersections. Capacity of signalised intersection is a function of cycle time, traffic composition, turning movement, capacity of slip lanes and pocket lanes, etc. (Radhakrishnan et. al.). Because of localized traffic flow and desire, it has been observed that certain intersections along arterial corridors are not only sight of extreme congestion but also act as bottleneck for whole neighbourhood road network. Reduced Level of Service (LOS) at only one or few signalised intersections in a road network is at times responsible for 
total jamming of road system in an area. This is one of the primary reasons for the recent push for smart and digital operation of signalised intersections.

\subsection{Smart and digital interventions in traffic signal operations}

The recent popularity of smart and digital interventions in operation of signalised intersections has demonstrated certain new and exciting techniques for monitoring and improving the traffic operations. Majority of smart interventions in operation of signalised intersections work upon the communication among vehicles and control system through various sensors and applications of artificial intelligence. Smart signal operations require the sensors grouted in pavement or attached with camera to share the relevant data in real time basis with central command and control centre. The decision to alter cycle time or any other intervention depends upon the marginal utility and 'advantage' of such action. The 'advantage' mentioned here can be in terms of flow rate, travel time, reduced emissions, priority to public vehicles etc. which has been further detailed in next section. The smart cities mission (SCM) of India, covering around 100 cities also focuses upon improving the urban mobility (Aijaz et. al.). Some of the popular proposals relating to smart operation of signalised intersection across shortlisted smart cities are - Adaptive and coordinated traffic signals, traffic command and control centre, priority to public and service vehicles, productive use of solar and mechanical energy, etc.

\section{Traffic signal optimisation}

\subsection{Concept of traffic signal optimization}

Signalisation of road intersections is primarily done to maximize traffic flow rate and road safety along with reducing the delay. The whole concept of adaptive signals and signal coordination is based upon dynamic data capture, synthesis, archiving and analysis using various available digital and conventional techniques (Misbahuddin et. al.). The generalised schematic principle of operations for smart signals at traffic intersections is presented in figure 1 with its various disaggregate components.

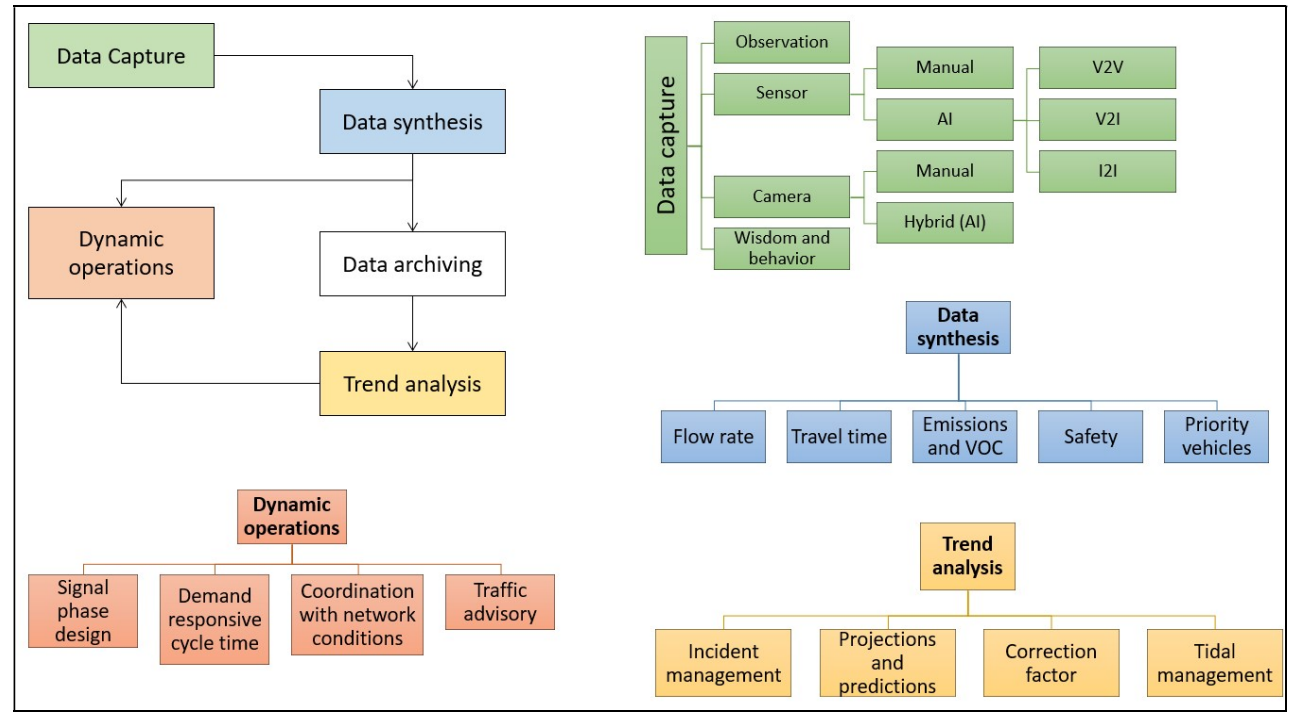

Figure 1 - Generalised schematic operation process at smart signals 
Data pertaining to various traffic characteristics like speed-flow variables, vehicular composition, directional turning volume at intersections, lane utilisation, etc. is captured at all critical cross-sections (intersections and varying Right of way cross-sections) using sensors and camera. Traditional understanding and field observations compliment the data so collected. Some of the worthy and upcoming mechanisms of 'smart' data collection using Artificial intelligence (AI) techniques are V2V (vehicle to vehicle), V2I (vehicle to infrastructure) and 12I (infrastructure to infrastructure) which are capable of handling large sets multi-variate data (Bento et. al.). The data so collected in real time is then synthesised and archived at the central command and control centre for city wide operations. Synthesised data is also considered for real time signal phase design and triggers decision to ensure efficient signal operations along the network. Based upon periodic data collection along the complete network, trend analysis is carried out w.r.t traffic projections, incident management, peak hour management, seasonal correction factors, tidal flow corrections, etc. which helps in retiming of signalised intersection operations. Based upon isolated adaptive traffic signal operations, the other signalised intersections of neighbourhood and corresponding corridors are knit together under the framework of coordinated traffic signal operations. As the name suggests, the biggest advantage of adaptive signals is its stimulus to dynamic traffic conditions. The adaptive signalised intersection in coordinated conditions is therefore expected to cater the local and neighbourhood traffic flow by updating cycle time and signal phase. Since each intersection would have various permutations of cycle time and phases, coordination of signalised intersections in a network is an extremely complex process. It shall be noted that the rational of signal coordination and adaption remains same - increased efficiency and safety along with reduced net delay. Some other smart techniques used at signalised intersections to improve the overall mobility includes sensors and transponders for 'priority vehicles', dynamic pedestrian and vehicular phasing using sensors and pelican switches. In this research, the traffic signal optimization using digital interventions refers to combination of one or more above mentioned techniques

\subsection{Evaluation of traffic signal optimization techniques}

With adaptive signal operations, it is attempted to schedule signal phases in such a way that green phase of every cycle generally experiences near saturated flow conditions. One of the most direct outcome of efficient signalised intersection optimization is improved traffic flow rate. There are many secondary benefits of improved throughput through signalised intersections like -

- reduced net delay for traffic operations in terms of vehicle-hours

- reduced net emissions and air pollution due to vehicular operations

- reduced noise pollution

- reduced fuel consumption and vehicle operating cost

It can be also argued that improved performance of signalised intersection would lead to safer vehicular operations throughout the network. Some of the long term behavioural and intangible benefits out of optimized signal operations are -

- better enforcement of law and order along the network of smart signals

- reduced road rage and improved on road mutual empathy

Another anticipated benefit of improved throughput through signalised intersection is reduced diversion of arterial and sub-arterial corridor traffic to the neighbourhood network in the want of congestion free corridors. Some scholars argue that manual marshalling of 
intersections is one of the most efficient and optimized ways of operating intersections as the stimulus and adaptations are prompt in this case. But it seems that manual marshalling is generally based upon local traffic experience and general wisdom which might not be able to process and coordinate with traffic characteristics in neighbouring network and intersections. In the light of above discussions, it seems that if implemented in true sense, signal optimization can lead to multifold benefits for our resources.

Although traffic signal optimization is still in its nascent days in a developing economy like India, the available limited experience and research highlights certain challenges w.r.t. the concept and process of optimization. As it has been already discussed in the previous section that traffic signal optimization is not a one-time action but rather a continuous process, the corresponding data archiving, data crunching, research and adaptations are indispensable for its success. This would necessitate robust infrastructure and skill capacities for the local traffic management agency. As the geometry, location and setting of each intersection in every network is bound to be unique, the optimization process needs to consider the same.

The dynamism in signal phasing and cycle timings might also lead to unpredictability and ambiguity among the road users. It would require reasonable awareness and time for the road users to assimilate and follow the signal optimization process. The bigger challenge here would be change and upgradation of the network geometry to put in place the required V2V and V2I communication systems. Also, it would be difficult for the signal optimization process to actualize its stated benefits unless driving and road user behaviour is in synchronization with the traffic optimization process at signalised intersections.

Another inevitable challenge leading out of improved signalised intersection operation would be augmented and induced traffic demand on the network. If at all, the level of service improves at signalised intersections along arterial roads and connected corridors, the private vehicle user might get tempted to be on road, who otherwise use public/shred transport. This would eventually increase the vehicles on road and the benefits of traffic signal optimization w.r.t. reduced delay may not be materialized. The above-mentioned phenomena, generally termed as 'vicious transport supply and demand cycle' is not unique to this intervention but it would be important to consider that the induced demand would pose challenges to the already complex signal optimization process.

\section{Challenges in traffic signal optimization}

As discussed in the previous section, traffic signal optimization requires each network and intersection to be attended individually because of its unique setting and role. It seems that traffic signal optimization cannot be attempted successfully using template-based upscaling approach because of the same reason. Further, most of the field knowledge relating to 'smart signals' and signalised intersection optimization is based on experiences of developed economy. The parameters and characteristics of traffic and corresponding signal optimization are bound to be different on Indian urban corridors. The following section discusses various challenges in Indian conditions relating to traffic signal optimization.

\subsection{Mix of hierarchy and functions}

Pertaining to ribbon development and bazaar culture, higher hierarchy corridors in Indian urban area are generally sight of commercial and mix landuse activities. This is mostly in 
contradiction to the primary function and utility of arterial corridors as mentioned in various codes of practices like IRC 106, UTTIPEC and IUT guidelines, etc. Because of this ambiguity in hierarchy and functions of such corridors, the road network and eventually signalised intersections don't end up using their full potential.

\subsection{Non - uniform road network}

Like non-uniformity in priority and hierarchy, non-uniform carriageway, ROW and street infrastructure is also responsible for inefficient traffic operations at intersections and corridor. This not only reduces the overall LOS along the road network but also triggers unauthorized use and encroachments along the unused stretches of ROW. The traffic signal optimization would require certain infrastructure and information technology systems to be installed along the ROW for data capture and in absence of suitable ROW, the process may get compromised. Similarly, intersections would also require suitable ROW to accommodate design and IT features.

\subsection{Side friction}

Various activities and features like on street parking, hawking and vending activities, kerb side bus stops, encroachments, frequent punctures for access streets, etc. are termed as side friction because of impedance offered by them to traffic flow operations. It has been observed that side friction is responsible for reduced traffic flow variables (speed, density and flow) and causes turbulence in the traffic stream. The phenomenon gets escalated and disrupts the traffic flow through intersections when significant side friction is observed near the intersections. It can be observed from Table 2 that along major arterial and sub-arterial corridors of many cities, the average intersection spacing is around $350 \mathrm{~m}$ and $200 \mathrm{~m}$ for major and minor intersections, respectively. These frequent conflict and decision areas reduce the overall LOS of traffic operations through the road network. At intersections, varying desires and movements of every vehicle requires it to merge and diverge more frequently and therefore, even minor side friction may impact the traffic operations severely.

\subsection{Heterogeneity in vehicular mix}

Urban roads are observed to have varying mix of vehicles operating along them with extreme heterogeneity in it. Table 3 represents the share of standard car and other modes during peak hour in a traffic mix along major corridors of few selected cities.

Table 3 - Mode share during peak hour traffic along major corridors of selected cities

\begin{tabular}{|c|l|l|c|c|c|c|}
\hline \multirow{2}{*}{ Sr } & \multirow{2}{*}{ City } & Corridor & $\begin{array}{c}\text { Peak hour } \\
\text { volume in } \\
\text { vehicles (PCU*) }\end{array}$ & $\begin{array}{c}\text { \% share of vehicles (PCU*) in stream } \\
\text { car }\end{array}$ & $\begin{array}{c}\text { Other } \\
\text { motorised }\end{array}$ & NMT $^{\#}$ \\
\hline 1 & Bhubaneswar & $\begin{array}{l}\text { Janpath - } 4.9 \\
\mathrm{~km}\end{array}$ & $2772(2230)$ & $21 \%(26 \%)$ & $64 \%(64 \%)$ & $\begin{array}{c}15 \% \\
(10 \%)\end{array}$ \\
\hline 2 & Agra & $\begin{array}{l}\text { M G Road - } \\
5.8 \mathrm{~km}\end{array}$ & $3612(2564)$ & $11 \%(15 \%)$ & $67 \%(66 \%)$ & $\begin{array}{c}22 \% \\
(19 \%)\end{array}$ \\
\hline 3 & Jaipur & $\begin{array}{l}\text { Tonk Road - } \\
\mathrm{km}\end{array}$ & $3937(3112)$ & $23 \%(29 \%)$ & $68 \%(64 \%)$ & $\begin{array}{c}09 \% \\
(06 \%)\end{array}$ \\
\hline 4 & Indore & $\begin{array}{l}\text { M G Road - } \\
4.1 \mathrm{~km}\end{array}$ & $5091(3664)$ & $21 \%(29 \%)$ & $76 \%(68 \%)$ & $\begin{array}{c}03 \% \\
(02 \%)\end{array}$ \\
\hline 5 & Patna & $\begin{array}{l}\text { Bailey \& Suri } \\
\text { road - 7.1 km }\end{array}$ & $4760(2644)$ & $10 \%(14 \%)$ & $78 \%(78 \%)$ & $\begin{array}{c}12 \% \\
(08 \%)\end{array}$ \\
\hline
\end{tabular}

Source - Primary data other than for Agra^ MG Road Improvement Study, SPA Delhi 2014

*Vehicle to PCU conversions based on IRC 106:1990

\# NMT - Non - motorized transport 
It is observed from Table 3 that urban roads cater to a variety of vehicles who share the same carriageway for travelling. Across all corridors, combined share of standard car and non-motorized modes vary from $22 \%$ to $36 \%$ whereas the classification of other motorized modes haves highest share. Modes like powered two-wheelers, auto rickshaw, tempo, bus and other freight vehicles comprise of this classification. Certain stretches along these corridors don't have a usable sidewalk and cycle track which forces pedestrians and cyclists, respectively to use the vehicular carriageway.

Since a mix of vehicles operate in such traffic streams, the clearances, headways, acceleration-deacceleration, turning radius, vision cone, etc. of individual vehicle type is different and therefore the streams become turbulent in nature towards saturation flow rates. Correspondingly, the maximum utilization of signal phases and cycles is generally not observed because of vehicle heterogeneity in the stream. The situation gets degraded further because of missing driving discipline and lane-based driving. It has also been observed that certain vehicle types are unique to Indian conditions and it requires certain changes in sensors and approach to include their characteristics in data collection and archiving.

\subsection{Tidal flow}

The distribution of landuse and aggregation of major attracting landuse in a settlement triggers time based skewed and unidirectional traffic flow rate along corridors which is generally referred as 'tidal flow'. The unique characteristic of such a phenomenon is extreme variation in saturation rate between the two directions of traffic flow along the corridor. The behaviour is specifically visible along divided carriageways as on undivided carriageway, the vehicles spill over to other side of carriageway diluting the concept of directional traffic congestion. One of the major challenges posed by tidal flow phenomenon is inefficient signal phases and cycle time unless dynamically tweaked using available knowledge. At times, certain algorithm might give us a signal time and phasing resulting into minimum delay per unit vehicle, but it may not be practically implementable because of driving behaviour. The concept has been illustrated using field data in subsequent sections. As tidal flow might be a recurring but not a periodic phenomenon, state of art signal optimization would require adaptations accordingly.

\subsection{Network characteristics}

Another challenge in traffic signal optimization arises from the fact that intersection efficiency is also a function of road network including the characteristics of preceding and succeeding intersections. Any sudden incident anywhere in the network demands quick calibration of signal phasing and cycle times across the network. There would be limited gain out of a highly calibrated and optimized signalised intersection if it is located among and around inefficient intersections and networks. Since each of the intersections in a network is characterized by its own unique geometry, flow rate and desire, the optimization attributes are bound to be different among intersections. As heterogeneous mix of vehicles use this network, the vehicle density and other traffic flow parameters are bound to be different across lanes and segments between two subsequent intersections. This signifies that efficiency optimization of standalone signalised intersection and coordination of signalised intersections in a network would not have exactly overlapping goals. Therefore, to improve the overall mobility experience and reduce the travel delay along any network, suitable 
appropriation might be needed at certain intersections. This would necessitate actions leading to purposeful deterioration of the LOS for specific standalone intersections to achieve better mobility experience along the corridor.

\subsection{Efficacy of optimization techniques}

The fundamental aim of signalised intersection optimization process is to achieve improved flowrate, speed, safety accompanied with reduced net delay to road users. Reduction in net delay along intersection and network can also be used as a yardstick to measure efficacy of optimization techniques. Average net delay per unit length with reference to free mean speed operations can be used to measure the impact of traffic signal optimization along the corridors. Similarly, average delay per vehicle (LOS criteria) can be used to measure the impact of traffic signal optimization at intersection, given that the traffic flow rates, and other conditions are not significantly altered. Both scales mentioned here seems to be not fully exclusive with each other and therefore their mutual relationship shall be studied. Unless not proved otherwise, it cannot be negated that reduction of delay at intersection because of traffic signal optimization will not lead to congestion along the surrounding corridor.

\section{Case study}

\subsection{Bhubaneswar}

Bhubaneswar is the administrative headquarter of Odisha state and is located around $70 \mathrm{~km}$ away from the Bay of Bengal in Khorda district. Famous for its beautiful temples and rich history, the core of present-day Bhubaneswar was designed by Otto Königsberger around 1948. Bhubaneswar is also one of the leading smart cities under Smart Cities Mission of India with various unique and state of art interventions for better quality of life for its users. One of the major components of smart cities mission is 'area-based development' (ABD) for which, Bhubaneswar town centre district (BTCD) along Janpath is being developed using retrofit and redevelopment approaches (Praharaj et. al.). As far as pan city development (PCD) proposals are concerned, one of the core and ambitious initiative is intelligent traffic management using smart signalised intersections. The central part of Bhubaneswar city is broadly aligned on grid-iron pattern with 4 major corridors running parallel to each other in north-south direction, connecting the Kharagpur-Chennai (NH16) National highway and is also relatively parallel to railway line. The $4.9 \mathrm{~km}$ long 'Janpath' stretch from 'Vani Vihar' intersection to 'Shishu Bhawan' intersection is host to most of the ABD as well as PCD interventions. Figure 2 represents the alignment of Janpath stretch in Bhubaneswar city.

Around 9 signalised intersections along Janpath are being upgraded with sensors and systems to reap the dividends of intelligent traffic management. As the surrounding landuse is primarily commercial and institutional along with some residential segments, on street parking and vending activities are frequently observed along the network. Although the onground carriage way width varies from 6 lanes to 8 lanes divided (18 to $25 \mathrm{~m}$ ), but pertaining to certain physical bottlenecks like on street parking, and low turning radius at punctures, effective carriageway gets reduced to 12 to $18 \mathrm{~m}$ at certain sections. The landuse along the Janpath stretch is also dominated by commercial landuse on one side of the corridor although residential and institutional landuse line the other side of the corridor. Figure 3 presents the carriage way variations and broad landuse along the Janpath stretch. 


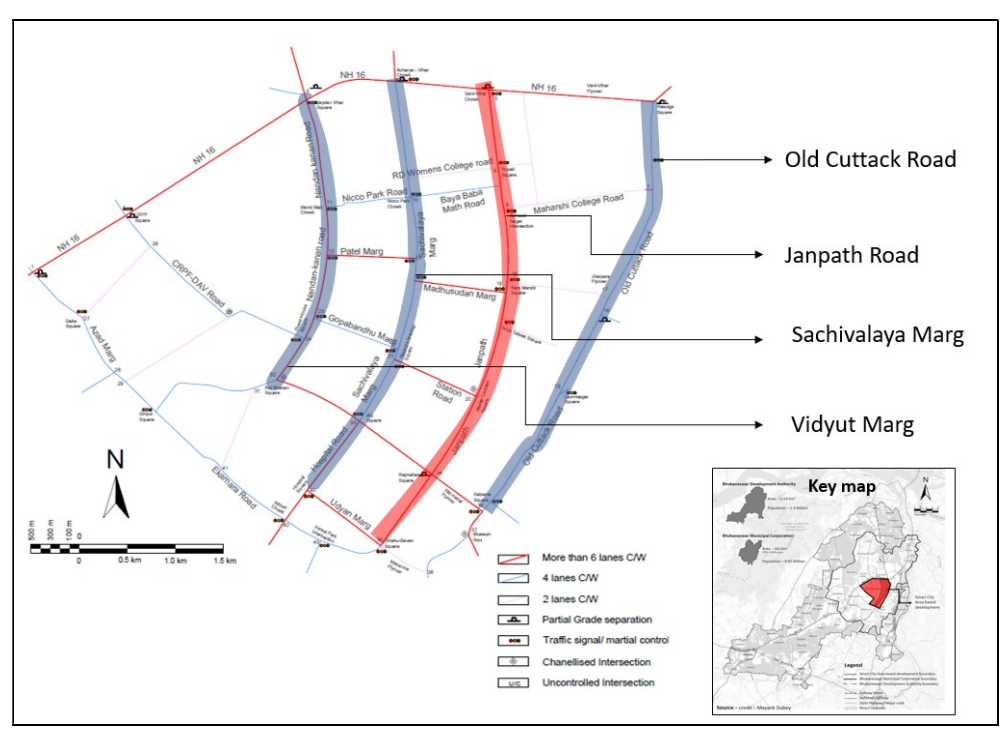

Figure 2 - Area based development in Bhubaneswar city as part of Smart Cities Mission

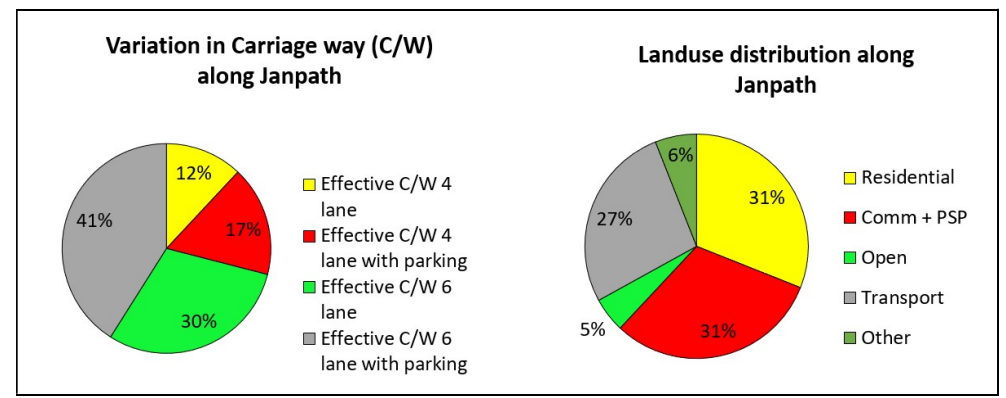

Figure 3 - Carriage way width and broad landuse classifications along Janpath Source - Primary survey

As mentioned in Table 2, the $4.9 \mathrm{~km}$ long Janpath corridor hosts around 37 minor and major intersections/punctures which significantly alters the functional utility of the corridor as primary arterial corridor. Figure 4 illustrates the major segments and intersections along the Janpath corridor.

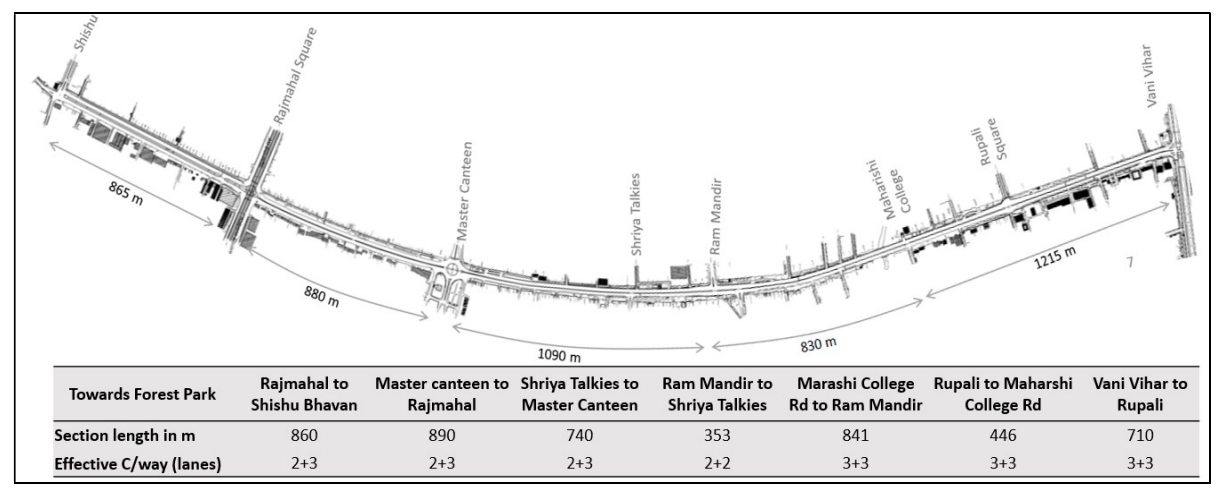

Figure 4 Major segments and intersections along Janpath Corridor 


\subsection{Traffic flow along Janpath}

The primary data collected along the Janpath corridor included traffic flow parameters speed, flow, density (derived using linear speed-density model); simultaneously at major intersections for 10 hours. The direction wise synthesised traffic flow data is presented in Table 4.

Table 4 - Direction wise traffic flow parameters along Janpath corridor

\begin{tabular}{|c|c|c|c|c|c|c|c|c|c|c|c|c|c|c|c|c|c|c|c|c|c|c|}
\hline \multirow{2}{*}{\multicolumn{2}{|c|}{$\begin{array}{c}\text { Section --> } \\
\text { Time }\end{array}$}} & \multicolumn{3}{|c|}{$\begin{array}{l}\text { Shishu Bhavan to } \\
\text { Rajmahal (3 lanes) }\end{array}$} & \multicolumn{3}{|c|}{$\begin{array}{l}\text { Rajmahal to Master } \\
\text { canteen ( } 3 \text { lanes) }\end{array}$} & \multicolumn{3}{|c|}{\begin{tabular}{|c|} 
Master Canteen to \\
Shriya Talkies ( 3 lanes)
\end{tabular}} & \multicolumn{3}{|c|}{\begin{tabular}{l|} 
Shriva Talkies to Ram \\
Mandir (2 lanes)
\end{tabular}} & \multicolumn{3}{|c|}{$\begin{array}{l}\text { Ram Mandir to Marashi } \\
\text { College Rd (3 lanes) }\end{array}$} & \multicolumn{3}{|c|}{$\begin{array}{l}\text { Maharshi College Rd to } \\
\text { Rupali (3 lanes) }\end{array}$} & \multicolumn{3}{|c|}{$\begin{array}{l}\text { Rupali to Vani Vihar (3 } \\
\text { lanes) }\end{array}$} \\
\hline & & $q$ & $\mathrm{k}$ & $\mathrm{v}$ & $q$ & $k$ & $v$ & q & $k$ & $v$ & 9 & $\mathrm{k}$ & $\mathrm{v}$ & $q$ & $k$ & $v$ & $q$ & $k$ & v & $q$ & $k$ & $\mathrm{v}$ \\
\hline \multirow{10}{*}{ 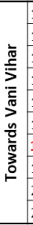 } & 1200 to 1300 & 2245 & 70 & 42 & 2600 & 80 & 35 & 2025 & 50 & 40 & 2050 & 75 & 25 & 1750 & 35 & 45 & 2050 & 45 & 40 & 2210 & 50 & 40 \\
\hline & 1300 to 1400 & 2640 & 75 & 37 & 2450 & 75 & 36 & 2430 & 75 & 36 & 2400 & 120 & 24 & 2050 & 50 & 45 & 2150 & 60 & 40 & 2560 & 80 & 35 \\
\hline & \begin{tabular}{|l|}
1400 to 1500 \\
\end{tabular} & 3085 & 100 & 27 & 2400 & 75 & 33 & 1890 & 50 & 40 & 2250 & 100 & 25 & 1825 & 50 & & 1890 & 40 & 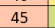 & 350 & 60 & 35 \\
\hline & \begin{tabular}{|l|}
1500 to 1600 \\
\end{tabular} & 2850 & 100 & 34 & \begin{tabular}{|l|}
1950 \\
\end{tabular} & 50 & 36 & 3040 & 100 & 30 & 2700 & 150 & 20 & 1740 & 40 & 45 & 2310 & 50 & 40 & 890 & 40 & 45 \\
\hline & \begin{tabular}{|l|}
1600 to 1700 \\
\end{tabular} & 3450 & 150 & 27 & 3240 & 120 & 30 & 3750 & 150 & 25 & \begin{tabular}{|l|}
3350 \\
\end{tabular} & 200 & 18 & 2560 & 75 & 35 & 2950 & 100 & 35 & 500 & 75 & 35 \\
\hline & \begin{tabular}{|l|}
1700 to 1800 \\
\end{tabular} & 4050 & 180 & 25 & 4460 & 225 & 20 & 4200 & 200 & 20 & 3680 & 200 & 18 & 3275 & 100 & 30 & 3620 & 125 & 30 & 050 & 100 & 30 \\
\hline & \begin{tabular}{|l|}
1800 to 1900 \\
\end{tabular} & 3990 & 270 & 15 & 4000 & 175 & 22 & 4040 & 200 & 20 & \begin{tabular}{|l|}
4050 \\
\end{tabular} & 300 & 15 & 3760 & 125 & 30 & 3580 & 110 & 50 & 400 & 150 & 25 \\
\hline & \begin{tabular}{|l|}
1900 to 2000 \\
\end{tabular} & 3775 & 160 & 24 & 3750 & 200 & 21 & 4190 & 200 & 20 & 3550 & 175 & 18 & 3345 & 100 & 27 & 3100 & 100 & . & 030 & 110 & 30 \\
\hline & 2000 to 2100 & 3820 & 200 & 19 & 3420 & 150 & 25 & 3350 & 100 & 30 & \begin{tabular}{|l|}
3050 \\
\end{tabular} & 150 & 19 & 2900 & 75 & 35 & 2540 & 60 & 38 & 2620 & 70 & 35 \\
\hline & \begin{tabular}{|l|}
2100 to 2200 \\
\end{tabular} & 2895 & 80 & 36 & 2660 & 75 & 36 & 2830 & 75 & 35 & 2560 & 110 & 24 & 2440 & 70 & 40 & 1630 & 30 & 50 & 2010 & 40 & 45 \\
\hline \multicolumn{2}{|r|}{ Section --> } & \multicolumn{3}{|c|}{$\begin{array}{l}\text { Rajmahal to Shishu } \\
\text { Bhavan (2 lanes) }\end{array}$} & \multicolumn{3}{|c|}{$\begin{array}{l}\text { Master canteen to } \\
\text { Rajmahal (2 lanes) }\end{array}$} & \multicolumn{3}{|c|}{$\begin{array}{c}\text { Shriya Talkies to Master } \\
\text { Canteen (2 lanes) }\end{array}$} & \multicolumn{3}{|c|}{\begin{tabular}{|c} 
Ram Mandir to Shriya \\
Talkies (2 lanes)
\end{tabular}} & \multicolumn{3}{|c|}{$\begin{array}{l}\text { Marashi College Rd to } \\
\text { Ram Mandir (3 lanes) }\end{array}$} & \multicolumn{3}{|c|}{$\begin{array}{l}\text { Rupali to Maharshi } \\
\text { College Rd (3 lanes) }\end{array}$} & \multicolumn{3}{|c|}{$\begin{array}{c}\text { Vani Vihar to Rupali (3 } \\
\text { lanes) }\end{array}$} \\
\hline & Time & $q$ & $\mathrm{k}$ & v & $q$ & $\mathrm{k}$ & v & 9 & $k$ & v & $q$ & k & v & 9 & k & v & 9 & $k$ & v & $q$ & $k$ & $\mathrm{v}$ \\
\hline \multirow{10}{*}{ 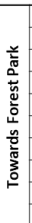 } & 1200 to 1300 & 1895 & 75 & 28 & 2235 & 100 & 25 & 1750 & 75 & 26 & 2000 & 75 & 30 & 2050 & 50 & 80 & 1780 & 35 & 45 & 2100 & 75 & 35 \\
\hline & \begin{tabular}{|l|}
1300 to 1400 \\
\end{tabular} & 2455 & 100 & 27 & 2460 & 100 & 25 & 2050 & 100 & 25 & 2450 & 100 & 25 & 1860 & 40 & 42 & 2050 & 50 & 40 & 1830 & 50 & 40 \\
\hline & \begin{tabular}{|l|}
1400 to 1500 \\
\end{tabular} & 2980 & 125 & 25 & 2560 & 125 & 23 & 2020 & 100 & 23 & 2290 & 100 & 77 & 1540 & 30 & 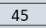 & 1520 & 25 & 5 & 1500 & 40 & 40 \\
\hline & \begin{tabular}{|l|}
1500 to 1600 \\
\end{tabular} & 3250 & 100 & 24 & 2780 & 125 & 24 & 2400 & 125 & 23 & 2500 & 100 & 25 & 1920 & 50 & 40 & 335 & 65 & 40 & 1950 & 50 & 40 \\
\hline & \begin{tabular}{|l|}
1600 to 1700 \\
\end{tabular} & 3675 & 140 & 21 & 3500 & 225 & 18 & 3250 & 20 & 20 & 3220 & 15 & 20 & 2890 & 100 & so & 3045 & 80 & 35 & 2690 & 100 & 30 \\
\hline & \begin{tabular}{|l|}
1700 to 1800 \\
\end{tabular} & 3900 & 200 & 14 & 4105 & 300 & 15 & 3750 & 300 & 13 & 3800 & 200 & 18 & 3600 & 150 & 25 & 3450 & 120 & 30 & 3450 & 200 & 20 \\
\hline & \begin{tabular}{|l|}
1800 to 1900 \\
\end{tabular} & 4015 & 175 & 18 & 4015 & 250 & 16 & 4020 & 250 & & \begin{tabular}{|l|}
050 \\
4050
\end{tabular} & 225 & & & 150 & 20 & & & & 3720 & 00 & 18 \\
\hline & \begin{tabular}{|l|}
1900 to 2000 \\
\end{tabular} & 3935 & 175 & 17 & \begin{tabular}{|l|l|}
4260 \\
\end{tabular} & 350 & 11 & 3840 & 200 & 16 & 3500 & 160 & 22 & 3110 & 100 & 28 & 3020 & 100 & 35 & 3100 & 150 & 22 \\
\hline & 2000 to 2100 & 3500 & 150 & 20 & 3480 & 150 & 20 & 3500 & 175 & 19 & \begin{tabular}{|l|}
3190 \\
\end{tabular} & 125 & 25 & 2560 & 75 & 35 & 2460 & 50 & 40 & 2470 & 75 & 32 \\
\hline & 2100 to 2200 & 3040 & 100 & 25 & 2570 & 100 & 23 & 3150 & 150 & 23 & 2550 & 75 & 33 & 2330 & 50 & 40 & 2130 & 50 & 40 & 2260 & 60 & 35 \\
\hline
\end{tabular}

Source - Primary survey

The Janpath corridor is divided in 7 segments and the data is presented in hourly window for 10 hours. The traffic flow rates along the corridor in either direction is almost similar and is getting saturated between 1800 to 1900 hours. Assuming an $80 \%$ ratio between Vehicles to PCU (Refer Table 3, corresponding to high share of powered two wheelers), the PCU values per lane per direction at extreme congested links, is around 1500 . This value is significantly higher and necessitates interventions to improve flow rate as corresponding speeds are observed to be around $15 \mathrm{kmph}$. The alarming situation of traffic congestion and saturation was one of the driving reasons for investing into Adaptive traffic control system (ATCS) and right of way (ROW) redesign as part of smart cities mission.

\subsection{Suitability for optimization}

Although Janpath corridor is of the hierarchy of arterial corridor for the town of Bhubaneswar, commercial establishments and high demand of on street parking along the corridor dilutes that hierarchy. As mentioned in Table 2, approximately 37 major and minor intersections are lined along the corridor making the corridor unsuitable for through desire. The average puncture spacing along the corridor is less than $150 \mathrm{~m}$, which makes it very difficult to implement any traffic management technique with efficacy. Based upon the traffic flow parameters observed in table 4 , and assuming jamming density of 400 vehicles per lane (based upon average vehicle length $=2.5 \mathrm{~m}$ ), the queue length generated by traffic signal operations along Janpath corridor is presented in Table 5.

Table 5 - queue length estimation using shockwave at intersections

\begin{tabular}{|l|l|l|l|l|l|l|}
\hline $\begin{array}{l}\text { Traffic } \\
\text { condition }\end{array}$ & $\begin{array}{l}\text { Flow (q) in } \\
\text { V/dir/hour }\end{array}$ & $\begin{array}{l}\text { Density } \\
(k) \text { in } \\
\text { V/dir/km }\end{array}$ & $\begin{array}{l}\text { Speed } \\
(v) \text { in } \\
\text { kmph }\end{array}$ & $\begin{array}{l}\text { Shockwave } \\
\text { speed }(\omega)\end{array}$ & $\begin{array}{l}60 \\
\text { queue } \\
\text { length }\end{array}$ & $\begin{array}{l}90 \\
\text { queue } \\
\text { length }\end{array}$ \\
\hline
\end{tabular}




\begin{tabular}{|l|l|l|l|l|l|l|}
\hline $\begin{array}{l}\text { Near } \\
\text { capacity }\end{array}$ & 4180 & 190 & 22 & $\begin{array}{l}19.9 \mathrm{kmph} \\
\text { or } 5.5 \mathrm{~m} / \mathrm{s}\end{array}$ & $\begin{array}{l}(5.5 * 60) / 3 \\
\text { lanes = 110 } \\
\mathrm{m}\end{array}$ & $\begin{array}{l}(5.5 * 90) / 3 \\
\text { lanes }=165 \\
\mathrm{~m}\end{array}$ \\
\hline Jamming & 0 & 400 & 0 & 0 & \\
\hline
\end{tabular}

Source - Deduced by author

As the average cycle time and corresponding waiting time at major intersections during peak hour is well beyond 90 seconds, a queue length of around $200 \mathrm{~m}$ is generally observed per phase along Janpath. This leads to the two way problem, one - the preceding junction to a signalised intersection is always prone to congestion locking because of backward propagating traffic congestion, two - the vehicles stop in the queue without leaving sufficiant headway leading to significant loss in head start during green phase.

Another challenge for optimised signal operation is full utilisation of green phase of the cycle time, which significantly depends upon the trend of straight and turning vehicles. A high share of turning movement at successive intersections corresponds to high share of local traffic interfering with through traffic. Table 6 presents the ratio between turning and straight moving vehicles.

Table 6 - Turning volume to straight moving vehicle ratio along Janpath during peak hour

\begin{tabular}{|l|l|c|}
\hline Serial & $\begin{array}{l}\text { Intersection } \\
\text { (chainage value in } \mathbf{~} \text { ) }\end{array}$ & $\begin{array}{l}\text { Ratio of turning vehicles/ } \\
\text { straight moving vehicles }\end{array}$ \\
\hline $\mathbf{1}$ & Rupali (710) & 1.1 \\
\hline $\mathbf{2}$ & Maharshi College (1156) & 0.8 \\
\hline $\mathbf{3}$ & Satya Nagar (1894) & 1.0 \\
\hline $\mathbf{4}$ & Ram Mandir (1997) & 1.8 \\
\hline $\mathbf{5}$ & Shriya Talkies (2350) & 0.8 \\
\hline $\mathbf{6}$ & Master Canteen (3090) & 2.1 \\
\hline $\mathbf{7}$ & Rajmahal (3980) & 1.7 \\
\hline \multicolumn{2}{|c|}{ Source - Primary survey } \\
\hline
\end{tabular}

The ratio between turning vehicles to straight moving vehicles along the seven intermediate intersections of Janpath corridor also suggests that the share local traffic is significantly higher along the corridor as compared to regional demand. As per the estimate from corridor wide origin - destination study (travel desire pattern), around $10 \%$ of the vehicles travel more than $4.0 \mathrm{~km}$ along the corridor (total length of corridor $(4.9 \mathrm{~km})$. This frequent mixing of local and linear traffic causes significant impedance and reduces the overall level of service along the corridor.

Traffic signal optimisation can yield its stated benefits if only there is uniformity and predictability in the support indicators of the traffic and corridor. The significant fluctuation in carriageway width, vehicle heterogeneity, local versus regional demand and frequent punctures are significant challenges for implementation of adaptive traffic control systems.

\subsection{Optimisation challenges}

Driving discipline, non-uniform road geometry, high rate of side friction and significantly higher flow rates are major challenges in using the smart signals. Even with excluding all other challenges, signalised intersections might not be as successful on such congested corridors because of the practical capacity of signalised intersections. Few intersections along Janpath are already experiencing more than 12000 vehicles of hourly inbound volume which necessitates grade separation and interchanges. The corridor either requires demand 
management (and reduction) to successfully reap the dividends of intersection signalisation or would require capacity augmentation in terms of wider/ multi tier corridors. In this regard, the suggestive approaches based upon field learnings and feedback from operating agencies is presented in subsequent section.

\section{Solutions for improved efficiency at traffic signals}

\subsection{Immediate/ short term}

- The right of way and carriage way shall be uniformly distributed to avaoid geometric bottlenecks. Extra slip lanes shall be provided to facilitate outgoing traffic so as to reduce the saturation levels and frequent side-punctures shall be restricted. If at all necessary then service roads can be used to dilute the impact of side punctures, parking and estaqblishments on primary arterial corridor.

- The hybrid and auxiliary lane marking (at least at the intersection influence zone) in heterogeneous traffic condition can help in optimising the stream movements. As vehicles tend to stop with negligible gaps between vehicles, this leads to significant accelerating and head start loss. Lane wise box marking or 3D holographic projections along each lane can be used to artificially infuse minimum gaps among vehicles in queue which can help in improving the flow rate at intersections. Although this would lead to increased queue length but would improve the flow rate because of simultaneous acceleration and movement of all vehicles in a lane. Figure 5 illustrates the lane wise box marking and corresponding gain in throughput.

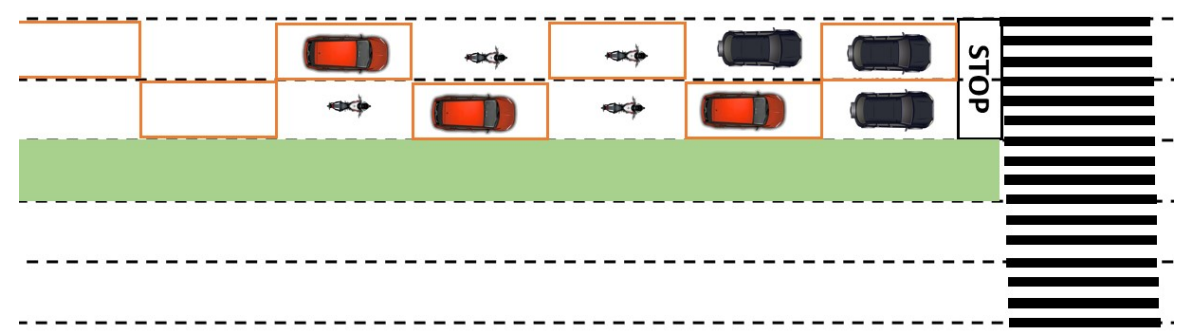

Figure 5 - Lane based box marking illustration

\subsection{Long term}

- Travel demand management and preferential treatment to non-private modes as part of policy intervention shall be carried out phase wise to optimise the corridor. Essentially this is demand management through optimising mode mix. Other techniques of travel demand management include restriction to specific modes (like heavy vehicles/slow vehicles/long vehicles, extra) for specific duration of the day to stagger the demand. Alternative corridors can also be developed to divert the traffic from existing corridors. Also, the conflicting traffic shall be segregated as they not only reduce the throughput but also cause unsafe operations. Here, conflicting traffic refers to one or more combination of following characteristics -

- Slow-fast (motorised - non motorised)

- Local-regional

○ Passenger-freight 
- Traditionaly driven-self driven

- Many of the on road incidents and conflicts can be avoided with standard driving conditions and discipline. Multiple mechanisms of improving on road awareness can definitely improve the capacity and level of service operations.

- Self driven and mutually communicating vehicles can also help ion improving the efficiency of operations as driving discipline and standard protocols can be expected to be better adhered. In a scenario where traditionally driven vehicles and self driven vehicles operate simultaneously in traffic streams, it would become indispensable to follow standard rules and discipline of operation.

\section{Conclusion}

Adaptive traffic control systems have improved the level of service and flow indicators significantly in those cases where uniformity in modes and right of way characteristics have been observed. Unlike them, the arterial corridors in many of Indian cities are host to varied kinds of heterogeneity. Leave apart smart signals, theses corridors are theoretically not even suitable for manually operated/marshalled signals because heavy flow rate and high side friction. To reap the true dividends of smart signals along such corridor, multiple simultaneous attempts are required to not only justify the investment but also to ensure that social, economical and environmental indicators are not getting deteriorated. In absence of such mechanisms, no significant gain can be evaluated out of smart signals.

\section{References}

Shriniwas S. Arkatkar (2018) "Traffic operations and capacity analysis in India", Transportation Letters, 10:2,65-67

Alam, M.A. and Ahmed, F., (2013) "Urban transport systems and congestion: a case study of indian cities", Transport and Communications Bulletin for Asia and the Pacific, 82, pp.33-43.

IRC, I.R.C., 1990. 106. (1990) “Guidelines for Capacity of Urban Roads in Plain Areas", Indian Roads Congress, New-Delhi (pp. 1-10).

Chandra, S. and Kumar, U., (2003) "Effect of lane width on capacity under mixed traffic conditions in India", Journal of transportation engineering, 129(2), pp.155-160.

Vaidya, C., (2009) "Urban Issues, Reforms, and Way Forward in India", Department of Economic Affairs, Ministry of Finance.

Government of Inidia, (2006) "National Urban Transport Policy, 2006”.

Curtis, C. and Tiwari, R., (2008) "Transitioning urban arterial roads to activity corridors", Urban Design International, 13(2), pp.105-120

Prashanth, L.A. and Bhatnagar, S., (2011, October), "Reinforcement learning with average cost for adaptive control of traffic lights at intersections", 14th International IEEE Conference on Intelligent Transportation Systems (ITSC) (pp. 1640-1645). IEEE. 
Radhakrishnan, P. and Mathew, T.V., (2011) "Passenger car units and saturation flow models for highly heterogeneous traffic at urban signalised intersections" Transportmetrica, 7(2), pp.141-162.

Aijaz, R. and Hoelscher, K., (2015) "India's Smart Cities Mission: An Assessment", ORF Issue Brief, 124, pp.1-12.

Misbahuddin, S., Zubairi, J.A., Saggaf, A., Basuni, J., Sulaiman, A. and Al-Sofi, A., (2015, December), "IoT based dynamic road traffic management for smart cities", 12th International Conference on High-capacity Optical Networks and Enabling/Emerging Technologies (HONET) (pp. 1-5). IEEE.

Bento, L.C., Parafita, R. and Nunes, U., (2012) "Intelligent traffic management at intersections supported by V2V and V2I communications", 2012 15th International IEEE Conference on Intelligent Transportation Systems (pp. 1495-1502). IEEE.

Praharaj, S., Han, J.H. and Hawken, S., (2018) "Urban innovation through policy integration: critical perspectives from 100 smart cities mission in India", City, culture and society, 12, pp.35-43. 